\title{
Effect of Modified Atmosphere Packaging on Quality of Barhi Dates at Khalal Stage
}

\author{
HAYDer JUmAAH Al-KAaBi ${ }^{\mathrm{a}}$ \\ ${ }^{a}$ Ministry of Higher Education and Scientific Research of Iraq \\ ${ }^{*}$ Corresponding author \\ haiderjk77@gmail.com \\ TEL: 009647723707416
}

Received: 31 January 2019; Published online: 18 January 2020

\begin{abstract}
Barhi Dates are an important food and often consumed and sold in the market during the stage Khalal, when the colour is yellow and their taste is sweet with the disappearance of their astringent taste. During the Khalal stage, these dates become physiologically mature with gives the sweet taste. For this reason, they are sold and consumed in a short period of time before these fruits turn into Rutab, a stage at which they lose that distinguishing characteristic. The high moisture, rapid ripening, and delays in transportation or improper storage conditions quickly result in Rutab stage. Thus The Khalal stage lasts for a short time until the fruits get ripe. In the present study, Barhi Khalals were packaged in air (control) and by two types of modified atmosphere packaging: MAP A $\left(5 \% \mathrm{O}_{2}+20 \% \mathrm{CO}_{2}\right.$ and $\left.75 \% \mathrm{~N}_{2}\right)$ and MAP B $\left(40 \% \mathrm{O}_{2}+20 \% \mathrm{CO}_{2}\right.$ and $\left.40 \% \mathrm{~N}_{2}\right)$. Afterwards, all samples were stored at $5^{\circ} \mathrm{C}$ for 30 days. On days zero, 10, 20 and 30 of storage, the fruits were evaluated in terms of the changes in thequality indices ofweight loss, colour, Total Soluble Solids (TSS), and firmness of the fruits and sensory features. The results showed that the minimum weight loss was $0.45 \%$ in modified atmosphere packaging, especially with MAP A and the minimum increase in the TSS was $37.35 \mathrm{Brix}^{\circ}$ after 30 days of the storage. On the other hand, the results for firmness, colour, and sensory evaluation were better with control packaging.
\end{abstract}

Keywords: Dates; Barhi; Khalal; Packaging; Quality

\section{Introduction}

The palm (Phoenix dactylifera L.) is one of the most successful fruiting trees in several arid and semi-arid regions of the world. It is considered an important subsistence crop (Awad, 2007). Date fruits are the main source of staple food in arid and semi-arid regions of North Africa, Middle East and South-Asian countries. They have always played an important role in the economic and social lives of people of this area (Hasnaoui et al., 2010). Iran has an annual production of more than 1,000,000 tonnes ( $15 \%$ of total world production) and it is considered the second largest producer of dates in the world (Rastegar, Rahemi, Baghizadeh \& Gholami, 2012). Dates are rich in certain nutrients and provide a good source of rapid energy, due to their high carbohydrate content (70-80\%). Moreover, date fruits contain fat $(0.20-0.50 \%)$, protein $(2.30-5.60 \%)$, dietary fibre (6.40-11.50\%), minerals (0.10-916 $\mathrm{mg} / 100 \mathrm{~g}$ dry weight), some vitamins (C, B1, B2, B3 and A) with very little or no starch (AlShahib \& Marshall, 2003). The developmental stages of date fruit are designated by the Arabic terms Hababouk, Kimri, Bisir or Khalal, Rutab and Tamar that represent, respectively, the cell division, cell elongation or the immature green, 


\section{Nomenclature}

MAP Modified Atmosphere Packaging
TSS Total Soluble Solids the mature firm full coloured, the soft brown and the hard raisin-like fruit (Awad, Al-Qurashi \& Mohamed, 2011a, 2011b).

Dates can be consumed at three stages of their development mainly Khalal, Rutab and Tamar depend on cultivar characteristics, especially level of soluble tannins, climatological conditions and market demand (Glasner, Botes, Zaid \& Emmens, 1999; Al-Qurashi \& Awad, 2011). Barhi dates, a commercially important mid-season cultivar, are consumed at the mature full yellow coloured stage (Khalal) as a crispy apple-like fruit. However, after harvest and/or during storage, especially at ambient conditions, the fruits rapidly become softer and sweeter (the Rutab stage) and lose much of their market value (Al-Qurashi \& Awad, 2011).

One of the primary technical challenges in marketing fresh Barhi fruits at the Khalal stage of maturity is the preservation of quality for the longest possible period after harvesting and during the marketing process. The proper packaging system should maintain the optimal storage, transport, and handling throughout the market chain for a specific commodity. Modified Atmosphere Packaging (MAP) has been beneficial in maintaining and extending the shelf life of several types of fresh produce. The MAP techniques rely on a modification of the atmosphere inside a package, achieved by the natural interplay between two processes: the respiration of the product and the transfer of gases through the package (Mahajan, Oliveira, Montanez \& Frias, 2007).

Generally, there are very few studies about the packaging of Barhi dates at Khalal stage by modified atmosphere packaging technique, one such being that of Al-Eid et al. (2012). In another study, Baloch, Salem, Baloch and Baloch (2006) examined Dhakki dates equilibrated at water activities of $0.52,0.58$ and 0.75 stored at +10 ${ }^{\circ} \mathrm{C}$ for 4 months under a controlled atmosphere of nitrogen, oxygen and air. The study indicated that the darkening and titratable acidity had increased, whereas the $\mathrm{pH}$ declined gradually during the storage of the dates. The change in the quality of date fruit appeared to be a function of storage atmosphere and water activity. However, Alhamdan and Al-Helal (2008) reported that there was no commercial method available to preserve fruit at the Khalal stage of maturity beyond the few days provided by traditional refrigeration methods. The aim of this research was to study the effects of modified atmosphere packaging of Barhi dates at Khalal stage at $5^{\circ} \mathrm{C}$ on Total Soluble Solids (TSS), weight loss, colour, firmness and sensory properties after 10, 20, 30 days of storage and compare it to control packaging.

\section{Materials and Methods}

\subsection{Sample Preparation}

Barhi dates at Khalal stage were collected from a local farm in Alflahyh city in east-south of Iran. After fruits were transported to the laboratory of food packaging at the College of Agriculture, Ferdowsi University, the dates were washed with potable water, sorted, weighed, prepared, and packaged into 10 fruits per bag $(20 \times 30 \mathrm{~cm})$ of three-layer polyethylene (LDPE), with a thickness of 80 microns. Two methods of packaging were used. The first method was control packaging by using plain air. The second method was by MAP, under two mixtures of three gases, MAP A $\left(5 \% \mathrm{O}_{2}+20 \% \mathrm{CO}_{2}\right.$ and $\left.75 \% \mathrm{~N}_{2}\right)$ and MAP B $\left(40 \% \mathrm{O}_{2}+20 \% \mathrm{CO}_{2}\right.$ and $\left.40 \% \mathrm{~N}_{2}\right)$ by introducing desired gas mixtures to the date samples and sealed using a Henkleman machine 
(Model 200A, Henkleman Vacuum Systems, Hertogenbosch, Netherlands). After that, samples were stored in conventional refrigerator at $5^{\circ} \mathrm{C}$ and relative humidity of $80-85 \%$ for 10,20 , and 30 days. Five fruits were selected from each bag for assessment. The assessment included the Total Soluble Solids (TSS), weight loss, colour, firmness and sensory properties with five replicates of one cluster per treatment.

\section{$2.2 \quad$ Weight loss}

Weight loss was determined by weighing the content of the packages before and after the storage period using an electronic weighing balance (ML3002.E, Mettler Toledo, Switzerland). Weight loss was expressed as the percentage of loss of weight with respect to the initial weight.

\subsection{Colour measurement}

Colour measurement was carried out using a Hunterlab ColorFlex EZ Spetrophotometer (Model 45/0. Hunter Lab, Virginia, USA). Measured parameters included the degree of lightness $(L)$, with $\mathrm{L}$ values ranging from 0 (black) to 100 (white); the ' $a$ ' value range from -100 (greenness) to +100 (redness) and the 'b' values range from 100 (blueness) to +100 (yellowness). These evaluations were conducted on three different date fruits in each package per three replicates. In addition, colour assessment was performed prior to treatment and on days 10, 20 and 30 of storage time (Ben Thabet et al., 2009).

\section{$2.4 \quad$ Firmness}

Firmness of Barhi Khalal dates was measured by using texture analyzer (Model RS-232, USA) with a cone weight of $102.3 \mathrm{~g}$ and a cone angle of $45^{\circ}$. Moreover, the firmness of the samples was expressed as the maximum compression force $(\mathrm{N})$, which was required to rupture the arils. All the tests were conducted at room temperature $\left(25^{\circ} \mathrm{C}\right.$ ) (Manolopoulou, Xanthopoulos, Douros \& Lambrinos, 2010).

\subsection{Total soluble solids (TSS)}

TSS were measured as degrees Brix (\%) in the date fruit juice using a refractometer (Atago,Tokyo, Japan), and adjusted with the border of zero between the dark- and light - coloured areas on the dates. Afterwards, two drops of the fruit juice were placed in a lens device, and the amount of TSS was determined (Association of Official Analytical Chemists, 1990).

\subsection{Sensory evaluation}

The sensory attributes of samples were evaluated at regular intervals in terms of colour, aroma, taste, appearance, texture and overall acceptability by a panel consisting of 10 trained evaluators using a five-point hedonic scale (5: excellent; 4: good; 3: acceptable; limit of marketability; 2 : poor and 1: extremely poor) (Larmond, 1977). Samples were randomly drawn from each experimental block, coded and served to the panelists randomly.

\section{Ethics and Consent}

The research followed the tenets of the Declaration of Helsinki promulgated in 1964 and was approved by the institutional human experimentation committee or equivalent, and that informed consent was obtained.

\section{Statistical analysis}

All data were processed by analysis of variance as a one-factor general linear model procedure (ANOVA) using SPSS (IBM, New York, USA) statistical software. The treatment means were separated using the least significant difference method. Differences at $\mathrm{P} \leq 0.05$ were considered as significant.

\section{Results and Discussion}

\subsection{Weight loss}

The weight loss throughout the storage time is demonstrated in Fig. 1. The weight loss of Barhi dates which were stored in natural air was $1.02 \%$ 
after $10 \mathrm{~d}$ of the storage, while with MAP A $\left(5 \% \mathrm{O}_{2}\right)$, it was $0.15 \%$, and with MAP B $\left(40 \% \mathrm{O}_{2}\right)$ it was $0.17 \%$. It was observed that if the storage time was increased, the weight loss also increased to $3.52 \%$ in the samples which were stored in natural air. Generally, at all the storage times in both the natural air and modified atmosphere packaging, there was a significant reduction in the time that the weight losses remained within acceptable limits. As show in Figure 1, there was a relation between the storage via MAP and the least weight loss in the dates.

This was mainly attributed to the loss of the moisture under air packaging conditions, while MAP-treated dates were enclosed in packages that prevented the loss of excess water content (Al-Eid et al., 2012). In this regard, findings of Al-Yahia (1986) indicated that the weight reduction of Barhi date during the storage is probably due to the loss of water contents. Al-Redhaiman (2004) reported that the weight loss of Barhi dates is an inversely proportional relationship between $\mathrm{CO}_{2}$ concentration at storing containers and the weight loss percent of the fruit. The highest percent of weight loss of the fruit was observed in control packaging in air, followed by low $\mathrm{CO}_{2}$ concentrations $(5 \%$ and $10 \%$, respectively), whereas the lowest percentage of the fruit weight loss was recorded for the fruits that were packed in $20 \% \mathrm{CO}_{2}$ gas mixture.

\subsection{Colour}

The colour of Barhi dates is light yellow at the Khalal stage and that is usually a major factor for the consumer preference. At the end of the Khalal stage, the intensity of the distinctive colour is increased and the colour of the fruits changes to light brown during the Rutab stage. These changes occur since the enzyme invertase starts to slowly increase during ripening at the end of the Khalal stage and then increases sharply (Hasegawa \& Smolensky, 1970; Hasegawa, Smolensky \& Maier, 1972)

In this study the changes of the colour are shown in Table 1. On days 10, 20 and 30 of the storage, the control packaging and MAP wassignificantly less yellow and light ( $L$ and $b$ ) and the change of the colour was variable. On the other hand, packaging by MAP A $\left(5 \% \mathrm{O}_{2}\right)$ had the least significant impact on the colour of the fruits where it was noticeably lighter, when compared with packaging by natural air and MAP B $\left(40 \% \mathrm{O}_{2}\right)$, which changed from yellow/brown to dark brown as shown. As shown in $L, b$ values in Table 1 . In addition, $a$ was higher in packaging with air and MAP B $\left(40 \% \mathrm{O}_{2}\right)$ than MAP A with $5 \% \mathrm{O}_{2}$. One of the reasons was the increasing concentration of nitrogen gas which was $75 \%$ with MAP A $\left(5 \% \mathrm{O}_{2}\right)$ (Kader \& Ben-Yehoshua, 2000). Furthermore, increasing the concentration of $\mathrm{CO}_{2}$ and decreasing $\mathrm{O}_{2}$ play an important role in reducing the respiration rate of the fruits. Roy, Anantheswaran and Beelman (1995) observed that the activity of tyrosinase which is responsible for mushroom browning is dependent on $\mathrm{O}_{2}$ concen $\neg$ tration. MAP induced higher $L$ values and lowered the difference between ideal mushroom target and sample compared with those observed by mushrooms being stored in non-MAP (control packages). After 27 days of the storage, all MAP-treated dates had significantly higher $\mathrm{b}$ values than the control dates, suggesting that MAP dates were notably more yellow in appearance than the control dates. Finally, the results of this study indicated that MAP A had some potential in reducing the rate of the colour storage in the Barhi dates packed at the Khalal stage of maturity and stored at $5^{\circ} \mathrm{C}$.

\subsection{Firmness}

The firmness of Barhi dates was significantly affected by the time period of the storage and packaging techniques during the storage (Figure 2). After 10, 20 and 30 days of the storage, firmness of all samples was observed to decrease so that the lowest values of MAP B $\left(40 \% \mathrm{O}_{2}\right)$ was 6.11 $\mathrm{N}$ after 30 days. On the other hand, the highest fruit firmness values were found in the control packaging at all storage days, because the nonpermeable film of bags increased the water vapor inside the bags which caused a decrease in the firmness of the fruits.

This was clearly seen with MAP B $\left(40 \% \mathrm{O}_{2}\right)$ because of the increase in $\mathrm{O}_{2}$ gas level. Dates at the Khalal stage are different from the rest because they do not ripen fully to reach the Rutap 


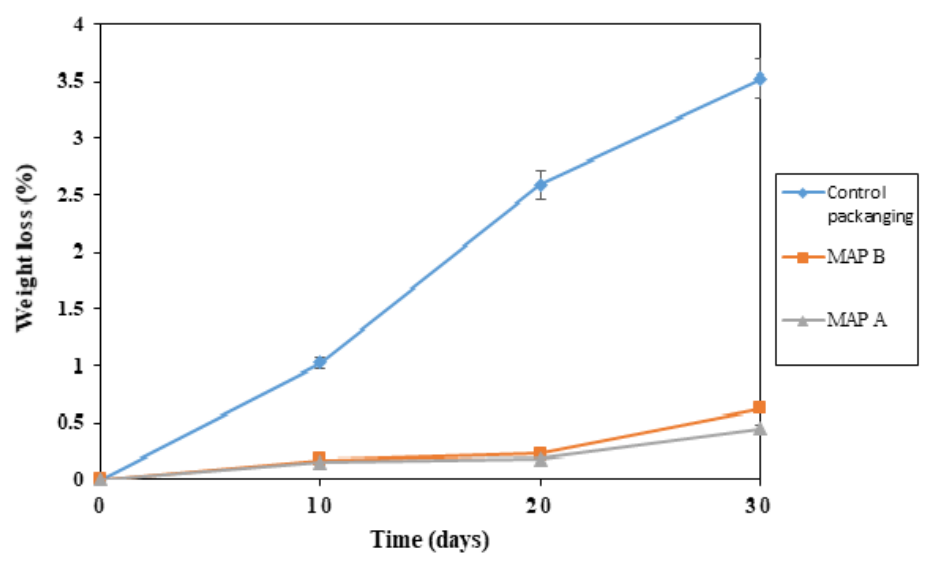

Figure 1: Weight loss for Barhi Khalal dates at $5^{\circ} \mathrm{C}$ over 10, 20, 30 days of storage

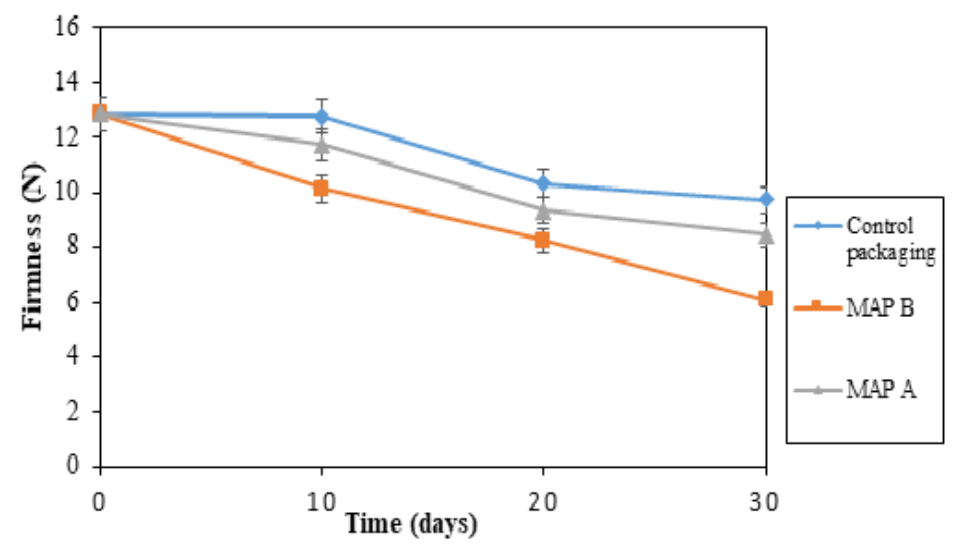

Figure 2: Effects of different atrmosphere packaging on the firmness of Barhi Khalal dates at $5^{\circ} \mathrm{C}$ over the 10, 20, 30 days of storage

and Tamar stages. So the high level of moisture leads to an increase in ripening Khalah dates. In addition, the ethylene gas produced by respiration of the fruits has an important role in accelerating the ripe of fruits (Jiang \& Fu, 2000; Al-Redhaiman, 2004; Saltveit, 1999). Moreover, the data indicated that the firmness of fruits was closely associated with the ripening process during the storage period, as lower firmness of the fruit was observed in the advanced stage of ripening. Al-Jasim and Al-Delaimy (1972) reported that increasing pectin esterase activity during the Khalal stage of ripening dates leads to the breakdown of pectin or softening of the fruits. In this regard, the enzymatic activity of pectin (pectin esterase and polygalacturonate) were the most important factors involved in softening of the fruit firmness. It should be noted that each factor may lead to the maintenance of the fruit firmness so delaying enzymatic activity (Mortazavi, Arzani \& Barzegar, 2007).

\subsection{Total Soluble Solids (TSS)}

The sugars of the date flesh mainly consist of fructose, glucose and sucrose. They are found 
SI130 | Al-Kaabi

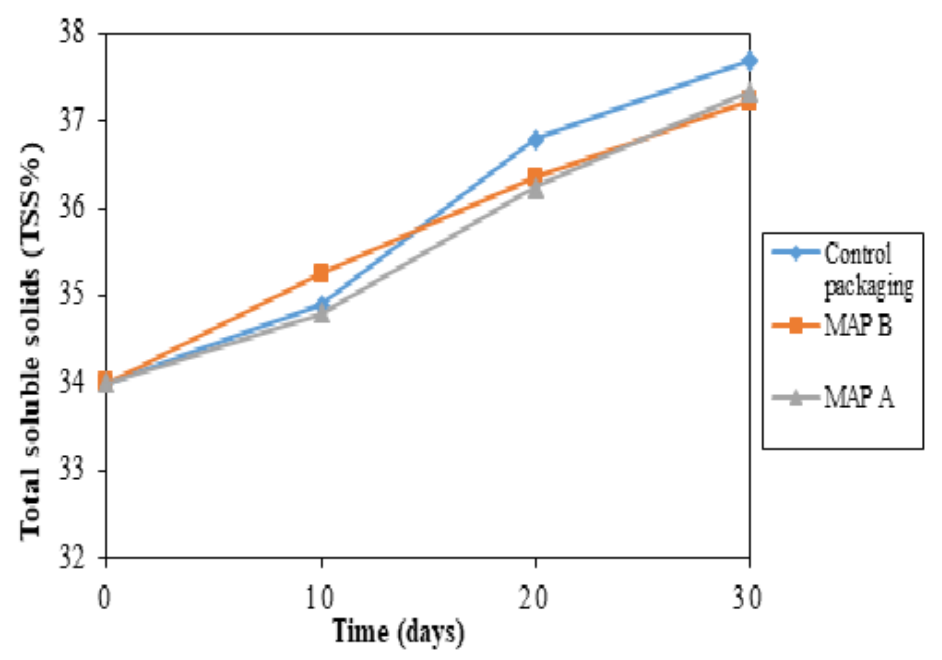

Figure 3: Effects of different atmosphere packag on TSS\% of Barhi Khalal dates at $5^{\circ} \mathrm{C}$ over 10, 20, 30 days of storage

Table 1: Colour changes for Bafhi Khalal dates stored in natural air (control) and modified atmosphere packaging after 30 days

\begin{tabular}{lllll}
\hline & \multicolumn{4}{l}{ Colour characteristics } \\
\hline Treatment & Time & $L$ & $a$ & $b$ \\
\hline Natural air & 10 & $49.95^{a}$ & $4.98^{c}$ & $39.93^{a}$ \\
MAP A & - & $49.44^{a}$ & $5.01^{a c}$ & $39.37^{a h}$ \\
MAP B & - & $47.87^{b}$ & $5.23^{a c}$ & $38.89^{h}$ \\
Natural air & 20 & $43.90^{h}$ & $5.23^{a c}$ & $33.76^{c}$ \\
MAP A & - & $42.78^{c}$ & $5.29^{a}$ & $32.74^{b c}$ \\
MAP B & - & $40.41^{d}$ & $5.66^{b}$ & $29.88^{f}$ \\
Natural air & 30 & $40.84^{d}$ & $5.82^{b h}$ & $32.64^{b}$ \\
MAP A & - & $39.44^{f}$ & $6.07^{h}$ & $27.81^{f}$ \\
MAP B & - & $37.54^{e}$ & $6.40^{g}$ & $30.41^{g}$ \\
Treatment & & $* *$ & $* *$ & $* *$ \\
Time & & $* *$ & $* *$ & $* *$ \\
Treatment $\times$ Time & & $\mathrm{NS}$ & $\mathrm{NS}$ & $* *$ \\
\hline
\end{tabular}

Values (mean of three replicates) in the same column followed by the same letter were not significantly

different by Duncan's test. NS, not significant.

$*, \mathrm{P} \leq / 0.05 ;{ }^{* *}, \mathrm{P} \leq / 0.01$.

All dates were assessed in air at room temperature

IJFS | January $2020 \mid$ Volume $9 \mid$ pages SI125-SI134 
Effects of MAP on Barhi dates | SI131

Table 2: Effect of modified atmosphere and control packaging on sensory attributes of Barhi Khalals dates over 10,20,30 days of storage at $5^{\circ} \mathrm{C}$

\begin{tabular}{lllll}
\hline & \multicolumn{4}{c}{ Colour characteristics } \\
\hline Treatment & Time & $L$ & $a$ & $b$ \\
\hline Natural air & 10 & $49.95^{a}$ & $4.98^{c}$ & $39.93^{a}$ \\
MAP A & - & $49.44^{a}$ & $5.01^{a c}$ & $39.37^{a h}$ \\
MAP B & - & $47.87^{b}$ & $5.23^{a c}$ & $38.89^{h}$ \\
Natural air & 20 & $43.90^{h}$ & $5.23^{a c}$ & $33.76^{c}$ \\
MAP A & - & $42.78^{c}$ & $5.29^{a}$ & $32.74^{b c}$ \\
MAP B & - & $40.41^{d}$ & $5.66^{b}$ & $29.88^{f}$ \\
Natural air & 30 & $40.84^{d}$ & $5.82^{b h}$ & $32.64^{b}$ \\
MAP A & - & $39.44^{f}$ & $6.07^{h}$ & $27.81^{f}$ \\
MAP B & - & $37.54^{e}$ & $6.40^{g}$ & $30.41^{g}$ \\
Treatment & & $* *$ & $* *$ & $* *$ \\
Time & & $* *$ & $* *$ & $* *$ \\
Treatment $\times$ Time & & $\mathrm{NS}$ & $\mathrm{NS}$ & $* *$ \\
\hline
\end{tabular}

Values (mean of five replicates) in the same column followed by the same letter were not significantly **, $\mathrm{P} \leq / 0.01, * *$ by Duncan's test. NS, not significant. $*, \mathrm{P} \leq / 0.05$

All dates were assessed in air at room temperature

as predominant sugars of dates from the different cultivars at the maturation level differing in proportions between the cultivars (Rastegar et al., 2012). At the beginning of this study, TSS of the Barhi Khalal was $34^{\circ}$ (Figure 3), while the total sugar content was observed to increase after 10,20, 30 days of storage, which occurred in all the treatments that the various rates (AlRedhaiman, 2004).

In this regard, the highest values were found in the control packaging for 10, 20 and 30 days, and the lowest values were found with MAP A $(5 \%$ $\mathrm{O}_{2}$ ). In general, the increased total sugar content associated with ripening of dates from the Khalal stage into the Rutab or Tamar stages will occur in the cells of the fruits when the moisture loss concentrates the sugar.

Bose (1985) reported that the control atmosphere $(\mathrm{CA})$ with high $\mathrm{CO}_{2}$ and low $\mathrm{O}_{2}$ concentrations or high $\mathrm{O}_{2}$ atmosphere had no significant influence on the TSS of apples and pears. Slow increases of the TSS of the control date may have been a result of the fresh dates being stored at the optimum storage temperature of $0^{\circ} \mathrm{C}$ (Kader
\& Hussein, 2009). In studying the TSS range of Khalal dates, it was estimated to be at $30-45^{\circ} \mathrm{C}$ Brix in three developmental stage, whilst it was $55-60^{\circ}$ Brix at the Rutab stage, and $60-84^{\circ}$ Brix at the Tamar stage.

\subsection{Sensory Attributes}

Sensory assessment of the samples was carried out on days 10, 20 and 30 of storage. Comparing MAP with natural air samples showed decreasing sensory scores in terms of overall acceptability for Barhi Khalal dates during the storage.

At the first 10 days, there was no significant difference $(\mathrm{p}>0.05)$ between MAP and control packaging. However there was a greater, more significant difference between MAP and control packaging on 20,30 days of storage $(\mathrm{p} \leq 0.05)$. In general MAP A had the best sensory properties compared with MAP B in the first 10 days, but there was no significant difference between MAP A and MAP B $(\mathrm{p}>0.05)$ in 20,30 days of the storage (Table 2). The highest quality of Barhi dates was found in the samples packaged at $5^{\circ} \mathrm{C}$

\begin{tabular}{l|l|l|l} 
IJFS | January 2020 | Volume 9 & pages SI125-SI134
\end{tabular} 
with the control packaging on all days of the storage, especially for the first 10 days, followed by MAP A after 10 days of storage.

Off-odour development has been attributed to fermentative metabolism under anaerobic conditions. Burton, E. Frost and Nichols (1987) recommended that for the storage of the mushroom Agaricus bisporus the oxygen level inside the packages must not fall below $3-4 \%$ in order to avoid anaerobic respiration. In active modified atmosphere packages, off-odours were detected after 12 days of the storage, when the oxygen concentration fell below $5 \%$. Thus, the results suggest that the $\mathrm{O}_{2}$ concentration must remain above $5 \%$ for Barhi Khalal dates in order to avoid off-odour generation. On the other hand, the off-odour development was the process responsible for loss of quality of Khalal Barhi dates stored in the control packages, but mainly it was because the fruit moved from the Khalal stage into Rutab. In addition, MAP B had a high $\mathrm{O}_{2}$ concentration with low sensory properties. This could be explained by assuming that Barhi Khalal deterioration could have been influenced by the high relative humidity inside the packages. The deterioration of the sensory attributes of some samples may have occured due to lactic acid bacteria or yeast growth, as the microbes were easily detected on account of giving bad flavours if present (Aidoo, Tester, Morrison \& MacFarlane, 1996). This finding indicated that the use of MAP did not improve the sensory quality of the Barhi Khalals over time in the storage period compared with the control -packaged dates.

\section{Conclusions}

These results showed that the packaging of Barhi date fruits in the Khalal stage in polyethylene bags (80 microns) using natural air and modified atmosphere packaging at the temperature of $5^{\circ} \mathrm{C}$ for 10, 20, 30 days storage, both MAP A $\left(5 \% \mathrm{O}_{2}\right.$ $+20 \% \mathrm{CO}_{2}$ and $\left.75 \% \mathrm{~N}_{2}\right)$ and MAP B $\left(40 \% \mathrm{O}_{2}\right.$ $+20 \% \mathrm{CO}_{2}$ and $40 \% \mathrm{~N}_{2}$ ) reduced the weight loss and the increase of TSS in the Barhi Khalal compared with the control but MAP was marginally better than MAP B. Neither MAP treatment was able to reduce deterioration, colour, firmness and sensory properties of the fruits over the storage period compared with the natural air packaging, though the loss of firmness was less under MAP A than MAP B. 


\section{Acknowledgements}

We extend our gratitude to Dr. Naser Sedaghat (Ferdowsi University of Mashhad, Iran) and Dr. Fereshteh Hosseini (ACECER, Khorasan Razavi, Iran) for their helpful suggestions in the visual quality analysis of the present study; we would also like to thank all the employees at the Agriculture Organization of Khorasan Razavi. Iran.

\section{References}

Aidoo, K. E., Tester, R. F., Morrison, J. E. \& MacFarlane, D. (1996). The composition and microbial quality of pre-packed dates purchased in greater glasgow. International Journal of Food Science and Technology, 31 (5), 433-438. doi:10.1046/j.1365-2621. 1996.00360.x

Alhamdan, A. \& Al-Helal, I. (2008). Effect of four storage systems on physical and mechanical properties of dates (khlass variety). Food Sci. \& Agric. Res. Center.

Association of Official Analytical Chemists. (1990). Retrieved from https : / / law . resource.org / pub/us / cfr / ibr / 002 / aoac . methods.1.1990.pdf

Awad, M. A. (2007). Increasing the rate of ripening of date palm fruit (phoenix dactylifera 1.) cv. helali by preharvest and postharvest treatments. Postharvest Biology and Technology, 43(1), 121-127. doi:10.1016/ j.postharvbio.2006.08.006

Awad, M. A., Al-Qurashi, A. D. \& Mohamed, S. A. (2011a). Antioxidant capacity, antioxidant compounds and antioxidant enzyme activities in five date cultivars during development and ripening. Scientia Horticulturae, 129(4), 688-693. doi:10.1016/j . scienta.2011.05.019

Awad, M. A., Al-Qurashi, A. D. \& Mohamed, S. A. (2011b). Biochemical changes in fruit of an early and a late date palm cultivar during development and ripening. International Journal of Fruit Science, 11 (2), 167183. doi:10.1080/15538362 . 2011.578520. eprint: https://doi.org/10.1080/15538362. 2011.578520
Baloch, M. K., Salem, S. A., Baloch, A. K. \& Baloch, W. A. (2006). Impact of controlled atmosphere on the stability of dhakki dates. LWT-food Science and Technology, 39(6), 671-676. doi:10.1016/j.lwt.2005.04.009

Ben Thabet, I., Besbes, S., Attia, H., Deroanne, C., Francis, F., Drira, N.-E. \& Blecker, C. (2009). Physicochemical characteristics of date sap "lagmi" from deglet nour palm (phoenix dactylifera 1.) International Journal of Food Properties, 12(3), 659-670. doi:10.1080/10942910801993528

Bose, T. K. (1985). Fruits of india: Tropical and subtropical.

Burton, K., E. Frost, C. \& Nichols, R. (1987). A combination plastic permeable film system for controlling post-harvest mushroom quality. Biotechnology Letters, 9, 529-534. doi:10.1007/BF01026655

Al-Eid, S. M., Barber, A. R., Rettke, M., Leo, A., Alsenaien, W. A. \& Sallam, A. A. (2012). Utilisation of modified atmosphere packaging to extend the shelf life of khalas fresh dates. International Journal of Food Science and Technology, 47(7), 1518-1525. doi:10.1111/j.1365-2621.2012.03000.x

Glasner, B., Botes, A., Zaid, A. \& Emmens, J. (1999). Date harvesting, packinghouse management and marketing aspects. date palm cultivation. FAO, Roma (Italia).

Hasegawa, S. \& Smolensky, D. C. (1970). Date invertase: Properties and activity associated with maturation and quality. Journal of Agricultural and Food Chemistry, 18(5), 902-904. doi:10.1021/jf60171a036

Hasegawa, S., Smolensky, D. C. \& Maier, V. P. (1972). Hydrolytic enzymes in dates and their application in the softening of tough dates and sugar wall dates. Rep Annu Date Grow Inst.

Hasnaoui, A., Elhoumaizi, M., Asehraou, A., Sindic, M., Deroanne, C. \& Hakkou, A. (2010). Chemical composition and microbial quality of dates grown in figuig oasis of morocco. International Journal of Agriculture and Biology, 12.

Al-Jasim, H. A. \& Al-Delaimy, K. S. (1972). Pectinesterase activity of some iraqi dates at different stages of maturity. Journal of 
the Science of Food and Agriculture, 23(7), 915-917. doi:10.1002/jsfa.2740230713

Jiang, Y. M. \& Fu, J. R. (2000). Ethylene regulation of fruit ripening: Molecular aspects. Plant Growth Regulation, 30(3), 193-200. doi:10.1023/A:1006348627110

Kader, A. A. \& Ben-Yehoshua, S. (2000). Effects of superatmospheric oxygen levels on postharvest physiology and quality of fresh fruits and vegetables. Postharvest Biology and Technology, 20(1), 1-13. doi:10.1016/ S0925-5214(00)00122-8

Kader, A. A. \& Hussein, A. M. (2009). Harvesting and postharvest handling of dates. ICARDA, Aleppo, Syria, 4, 15. Retrieved from http: / / www . doc-developpement durable . org / file / Arbres - Fruitiers / FICHES_ARBRES / Palmier - dattier / Project \% 20on \% 20the \% 20Development \% 20of $\%$ 20Sustainable $\%$ 20Date $\%$ 20Palm \% 20Arabia.pdf

Larmond, E. (1977). Laboratory methods for sensory evaluation of food. research branch, canada department of agriculture, publication 1637. Food Research Institute, Ottawa, Ont.

Mahajan, P., Oliveira, F., Montanez, J. \& Frias, J. (2007). Development of user-friendly software for design of modified atmosphere packaging for fresh and fresh-cut produce. Innovative Food Science \& Emerging Technologies, 8(1), 84-92. doi:10.1016/j.ifset. 2006.07.005

Manolopoulou, H., Xanthopoulos, G., Douros, N. \& Lambrinos, G. (2010). Modified atmosphere packaging storage of green bell peppers: Quality criteria. Biosystems Engineering, 106(4), 535-543. doi:10.1016/j. biosystemseng.2010.06.003

Mortazavi, S. M. H., Arzani, K. \& Barzegar, M. (2007). Effect of vacuum and modified atmosphere packaging on the postharvest quality and shelf life of date fruits in khalal stage. In A. Zaid, V. Hegarty \& H. AlKaabi (Eds.), Proceedings of the iiird international date palm conference (736, pp. 471+). Acta Horticulturae. 3rd International Date Palm Conference, Abu Dhabi, U ARAB EMIRATES, FEB 19-21, 2006. United Arab Emirates Univ; UN Dev
Programme; FAO; Int Soc Hort Sci; Int Soc Food, Agr \& Environm; Arab Author Agr Investment \& Dev; Date Palm Global Network; A1 Wathba Marionnet; Green Coast Nurseries; Municipalities \& Agr Dept, Municipal Sector, Al Ain. doi:10. 17660/ActaHortic.2007.736.45

Al-Qurashi, A. D. \& Awad, M. A. (2011). Naphthaleneacetic acid increase bunch weight and improve fruit quality of'barhee'date palm cultivar under hot arid climate. American-Eurasian Journal of Agricultural E Environmental Sciences, 10(4), 569-573.

Rastegar, S., Rahemi, M., Baghizadeh, A. \& Gholami, M. (2012). Enzyme activity and biochemical changes of three date palm cultivars with different softening pattern during ripening. Food Chemistry, 134(3), 1279-1286. doi:10.1016/j.foodchem. 2012. 02.208

Al-Redhaiman, K. N. (2004). Modified atmosphere improves storage ability, controls decay, and maintains quality and antioxidant contents of barhi date fruits. Journal of Food Agriculture \& Environment, 2(2), $25-32$.

Roy, S., Anantheswaran, R. C. \& Beelman, R. B. (1995). Fresh mushroom quality as affected by modified atmosphere packaging. Journal of Food Science, 60(2), 334-340. doi:10 . 1111/j.1365-2621.1995.tb05667.x

Saltveit, M. E. (1999). Effect of ethylene on quality of fresh fruits and vegetables. Postharvest Biology and Technology, 15(3), 279292. doi:10.1016/S0925-5214(98)00091-X

Al-Shahib, W. \& Marshall, R. J. (2003). The fruit of the date palm: Its possible use as the best food for the future? International Journal of Food Sciences and Nutrition, 54 (4), 247259. doi:10.1080/09637480120091982

Al-Yahia, S. A. (1986). Quality change of 'barhy'dates during storage at bisr stage. In Proceedings of the second symposium on the date palm in saudi arabia. march 3 (Vol. 6). 